\title{
Analysis of a Tropical Warm Spring Microbiota Using 16S rRNA Metabarcoding
}

\author{
Deborah Fasesan ${ }^{1,2}$, Karim Dawkins ${ }^{3}$, Roberto Ramirez ${ }^{3}$, Hadiza Rasheed-Jada ${ }^{1}$, \\ Abiodun Onilude ${ }^{2}$, Oyekanmi Nash ${ }^{1 *}$, Nwadiuto Esiobu ${ }^{3 *}$ \\ ${ }^{1}$ Center for Genomics Research and Innovation, National Biotechnology Development Agency, Abuja, Nigeria \\ ${ }^{2}$ Department of Microbiology, University of Ibadan, Ibadan, Nigeria \\ ${ }^{3}$ Microbial Biotechnology Laboratory, Florida Atlantic University, Boca Raton, USA \\ Email: *oyekan.nash@gmail.com, *nesiobu@fau.edu
}

How to cite this paper: Fasesan, D., Dawkins, K., Ramirez, R., Rasheed-Jada, H., Onilude, A., Nash, O. and Esiobu, N. (2020) Analysis of a Tropical Warm Spring Microbiota Using 16S rRNA Metabarcoding. Advances in Microbiology, 10, 145-165. https://doi.org/10.4236/aim.2020.104012

Received: February 22, 2020

Accepted: April 12, 2020

Published: April 15, 2020

Copyright (C) 2020 by author(s) and Scientific Research Publishing Inc. This work is licensed under the Creative Commons Attribution International License (CC BY 4.0)

http://creativecommons.org/licenses/by/4.0/ Open Access

\section{Abstract}

The Ikogosi Warm Spring is a unique ecological niche in Western Nigeria with an average temperature and $\mathrm{pH}$ of $38^{\circ} \mathrm{C}$ and 5.8 respectively. It mixes with an adjacent cold spring $\left(28^{\circ} \mathrm{C} \& \mathrm{pH} 7.6\right)$, about 100 meters from source, yielding a confluence body of water of $32^{\circ} \mathrm{C}$ and $\mathrm{pH}$ 7.7. To explore the bacterial community structure of this uncommon environment and to scan for potentially useful bacteria, metagenomes extracted directly from five samples (source and mid-point of warm spring; source and midpoint of cold spring, and the confluence) were analyzed. Using the MiSeq Illumina next generation sequencing protocols, the V3-V4 region of the 16S rRNA gene pool was sequenced and analyzed by QIIME (Quantitative Insights into Microbial Ecology) and R software. At least $11 \%(47,446)$ of all the sequences were unknown to any of the databases employed. Bacterial diversity and abundance at the source of both springs were extremely low, accounting for less than $0.07 \%$ of the total sequence reads at the confluence, $100 \mathrm{~m}$ downstream. In contrast to the highly diversified mesophilic confluence community where 21 different phyla were identified, only 4 and 5 phyla were recovered from the source-point of the warm spring and cold spring respectively. The most prevalent phyla in all samples were members of the versatile Proteobacteria (35\% - 50\% relative abundance), and the hardy Firmicutes $(33 \%-40 \%)$. Operational taxonomic units (OTUs) obtained from all the samples averaged at 1414. Temperature and $\mathrm{pH}$ were equally significant predictors of genomic diversity and richness, with the warm and cold spring sources having less than 5 bacteria phyla. Exiguobacterium sp. (a potential plastic degrader) and other deep rooted bacteria were found in the warm spring while the cold spring outflow contained among others such asRubrobacter sp. and Chloroflexi sp. (which is close to the phylogenetic root of the domain Bacteria). Many taxonomically 
unresolved sequences could indicate the presence of potentially novel bacteria in this unique body of water and underscores the need to systematically mine these rare genetic reservoirs for biotechnological applications. Moreover, such tropical hydrothermal ecosystems could contain some unknown primitive bacteria at the origins of life.

\section{Keywords}

Ikogosi Warm Springs, Amplicon Metagenomics, Next-Gen Sequencing, QIIME, Bacterial Diversity Source

\section{Introduction}

Ikogosi Warm Spring is one of the natural touristic hot spots in South Western Nigeria. It is located about $2 \mathrm{~km}$ west of Ikogosi town on longitude $4^{\circ} 56.46^{\prime} \mathrm{E}$ and latitude $7^{\circ} 36.88^{\prime} \mathrm{N}$ [1]. The warm spring flows down a hilly landscape beautified by tall ever-green trees which form a restful canopy for visitors. In a captivating turn, it mixes with a cold spring, originating from a distant independent source to form one merged flowing stream [2] [3] whose banks and sediments appear dark and moist. Tourists' activities are normally restricted to the peak of the confluence of the springs. At the midpoint of the warm spring, the villagers fetch water for cooking and drinking purpose. Anthropogenic impact at both sources of the spring, and at the midpoint of the cold spring is relatively low. This interesting ecological niche is an important tourist attraction of the country, tucked away in the serene and rustic town of Ikogosi. The area has numerous touristic values stretching from historical monuments, traditions and the people, to other forms of tourist features. The spring has been known for its continuous flow for very many years and is a major source of portable water for over 30,000 residents of Ikogosi-Ekiti town [4].

Natural environments often harbor more diversity of microorganisms, than has been identified or characterized [5]. In recent years, the use of amplicon sequencing and full metagenomics, culture independent approaches for studying microbial community structure from environmental niches allows for the identification of both cultivable and presently unculturablebacteria [6] [7] [8]. In addition, metagenomics studies eliminate the culture bias by directly recovering bacterial groups in their naturally occurring relative abundance; shedding light into the functional dynamics and complex biochemical processes of an environment. Documenting the microbial diversity of very old and unique niches is important to understanding the phylogenetic grouping of extant lineages. The widely held notion that spring water sources are portable without any tests needs to be examined. The Ikogosi streams present a good model for tracking the potential sources, bacterial diversity and richness of microorganisms found downstream. Thermal springs have been known to contain bacteria of unique physiology and attributes such as the Thermus aquaticus whose economic and scien- 
tific benefits and applications are enormous [9] [10].

There are no reports of a systematic study of the microbiomes of the important spring in western Nigeria. A study in 2005 [11], used conventional culture techniques to screen soil samples from around the warm spring for proteaseproducing bacteria and presumptively found only four phylotypes. Although this study found very scanty bacteria diversity at the source of the aquatic niche, it identified phylotypes such as-the Fusobacterium which were not detected in the culture-limited study of the sediment. Usually, the sediment of springs and rivers contain a much higher diversity and many logs more abundant bacteria than the water phase [12] [13] [14] [15]. As a first step towards exploring this important niche for eventual harnessing of potentially useful bacteria; this brief study employs $16 \mathrm{~S}$ rRNA amplicon sequencing of metagenomic DNA to profile bacteria composition of the niches. The difficulty of cultural potentially interesting mesophilic and psychrophilic oligotrophs in natural environments can be surmounted after culture-independent methods are used to profile the exact types of organisms present. This research is the first to employ next generation sequencing of a conserved chronometric gene (amplicon metagenomic approach) to define the bacteria community structure in this marvel of nature-Ikogosi springs.

\section{Materials and Methods}

\subsection{Sample Collection}

Water samples from the spring (Figure 1) were collected using sterile vials, from the point of outflow (Source) of the warm spring (S1), the midpoint of the warm

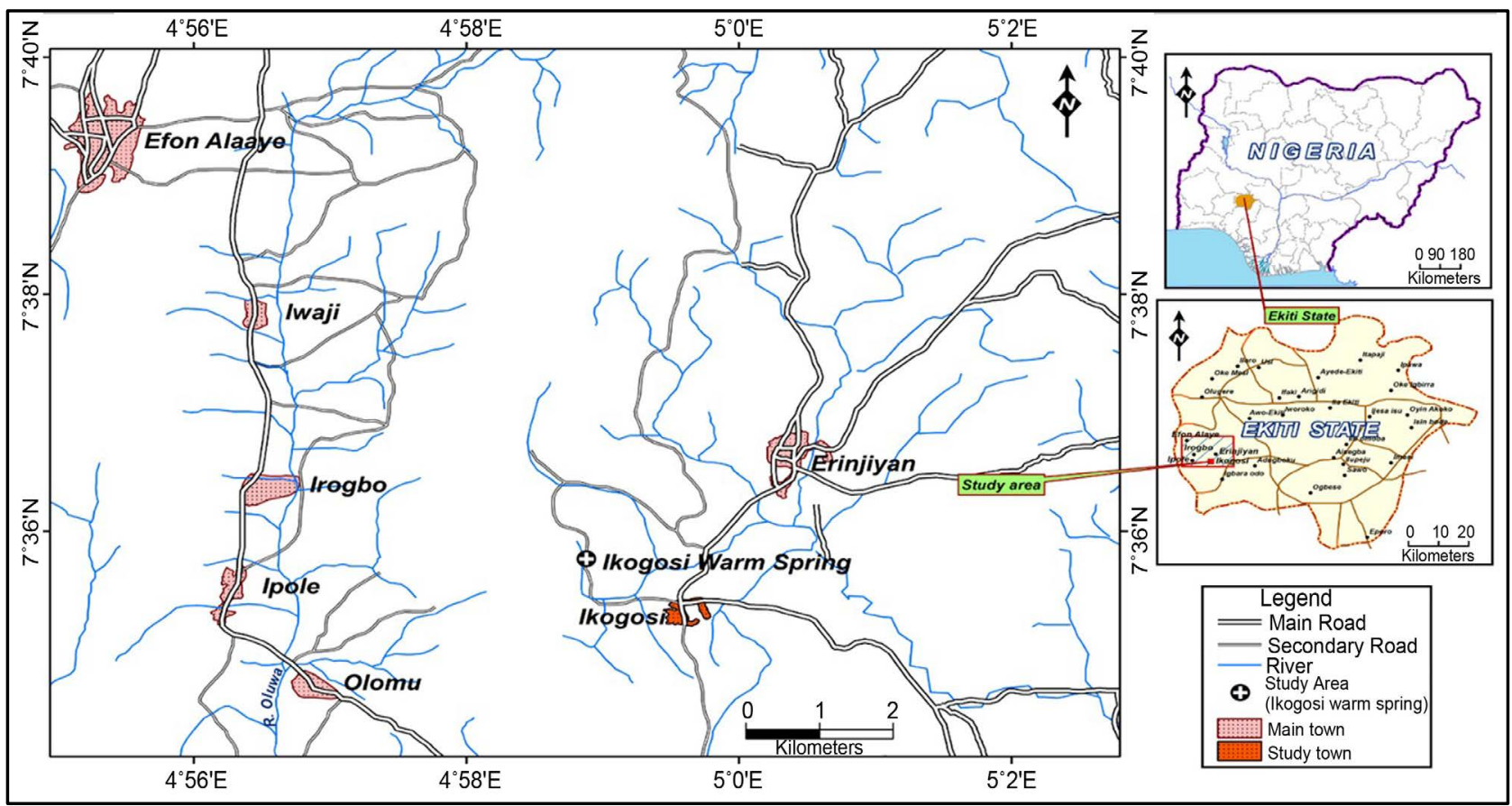

Figure 1. Map of study area and its surrounding environment in Ekiti, South Western Nigeria. 
spring (S2), the midpoint of the cold spring (S4), designated point of outflow (Source) of the cold spring (S5) and from the confluence of both springs (S3). This was done by lowering sterile bottles to the bottom of the relatively shallow spring with the aid of a gloved hand. Samples were then transported to the laboratory and stored at $4^{\circ} \mathrm{C}$ until analyzed.

\subsection{DNA Extraction}

Water samples were vigorously shaken to resuspend bacterial cells. Then $1.5 \mathrm{ml}$ of each sample was aliquot into 10 microcentrifuge tubes and spun at 15,000 rpm for 10 minutes (to pellet the cells). The supernatants were carefully decanted, and the steps were repeated 10 times with the same tubes resulting in pelleted bacteria from a total of $15 \mathrm{ml}$ of water sample per tube. The bacteria pellets were subsequently pooled into one tube by adding 100 microliters of sterile Phosphate buffered saline (PBS) to the first tube, re-suspending the cells and transferring the entire content into the next tube. Process was repeated 9 times, ultimately harvesting all the cells in $150 \mathrm{ml}$ of water into one microcentrifuge tube. Genomic DNA in the spooled cells was then extracted using AccuPrep ${ }^{\circ}$ Genomic DNA Extraction Kit (Bioneer Corporation, Korea) following the manufacturer's instruction.

\subsection{Library Construction, Amplification and Sequencing}

The single index Mi-Seq protocols were employed to sequence the V3-V4 region of the $16 \mathrm{~S}$ rDNA gene of the samples from Ikogosi Warm Spring.

\subsection{DNA Concentration and Purity}

In order to assess the quality of the extracted DNA samples for PCR analysis, the DNA concentration and purity of each sample was measured using the Nanodrop 2000c spectrophotometer (Thermo Fisher Scientific, MA, USA). Extracted samples were also run on a $1 \%$ agarose gel $(1 \times \mathrm{TAE})$ at $90 \mathrm{~V}$ for $45 \mathrm{mins}$ to visually verify the integrity of the samples.

\subsection{Initial Amplification of Extracted Bacterial DNA}

To confirm that the extracted DNA can be sequenced by amplification; the bacterial $16 \mathrm{~S}$ rDNA, a chronometer gene found in all bacteria (Figure 2) was amplified using the universal primer 1492 Reverse (5'GGTTACCTTGTTACGACTT-3') and 27 Forward (5'-AGAGTTTGATCCTGGCTCAG-3'). The primers pair flank the V1-V9 region of the 16S rDNA gene, yielding an amplicon of about 1500 base pairs (Figure 2). Reaction mixtures (1× Promega master mix, 50 ng DNA template, $0.5 \mathrm{uM}$ of each primer) were incubated for $4 \mathrm{mins}$ at $94^{\circ} \mathrm{C}$ for denaturation, followed by 35 cycles consisting of $1 \mathrm{~min}$ at $94^{\circ} \mathrm{C}$, annealing for $30 \mathrm{~s}$ at $45^{\circ} \mathrm{C}$, and extension for 2 mins at $72^{\circ} \mathrm{C}$. Four $(4 \mu \mathrm{l})$ microliters of PCR product was run using gel electrophoresis in a $1 \%$ agarose $(\mathrm{w} / \mathrm{v})$ gel at $90 \mathrm{~V}$ for $45 \mathrm{mi}-$ nutes. 


\begin{tabular}{|c|c|c|c|c|c|c|c|c|c|c|c|c|}
\hline o 100 & 200 & $0 \quad 300$ & 400 & 500 & 600 & 700800 & 900 & 1000 & 1100 & 1200 & 1300140 & $01500 \mathrm{~b}$ \\
\hline V1 & & V2 & & V3 & & V4 & Vt & & V6 & V7 & V8 & V9 \\
\hline
\end{tabular}

Figure 2. 16S rRNA gene showing the V1-V9 varaibale regions and conserved regions. The 515F/806R primer pair amplifies within the V3-V4 region.

\subsection{Preparation of Extracted Metagenomic DNA for Sequencing}

The DNA samples were first quantified using the Qubit 2.0 fluorometer according to manufacturer's instructions (Thermo-Fisher Scientific Inc., MA, USA) and subsequently diluted as needed to $5 \mathrm{ng} / \mu \mathrm{l}$ according to the Illumina sequencing protocol. The Illumina recommended-primer pair-515F and 806R [16], which binds bacterial/archeal regions $515 \mathrm{~F}$

(5'-AATGATACGGCGACCACCGAGATCTACACTATGGTAATTGTGTGCC AGCMGCCGCGGTAA-3') and 806R (5'-CAAGCAGAAGACGGCATACGAGAT AGTCAGTCAG CC

GGACTACHVGGGTWTCTAAT-3') were used to target the V3-V4 region of the 16S rDNA sequence (Figure 2). The PCR cocktail contained 515F/806R primers at $0.2 \mu \mathrm{M}$ each and 5-Prime hot-start master mix (5 PRIME Inc. MD, USA), $5 \mathrm{ng}$ DNA template plus molecular grade water to produce a $25 \mu \mathrm{l}$ total reaction volume. The thermocycler conditions used were $94^{\circ} \mathrm{C}$ for 3 minutes, 35 cycles of $94^{\circ} \mathrm{C}$ for 45 seconds, $50^{\circ} \mathrm{C}$ for 1 minute, and $72^{\circ} \mathrm{C}$ for 90 seconds, followed by a final elongation for 10 minutes at $72^{\circ} \mathrm{C}$.

Four $(4 \mu \mathrm{l})$ microliters of the amplified products (approximately $300 \mathrm{bp}$ ) were run on a $1.5 \%$ agarose gel $(0.5 \% \mathrm{TAE})$ at $70 \mathrm{~V}$ for 45 minutes to validate the amplicon size using a $100 \mathrm{bp}$ ladder.

\subsection{Library Construction-PCR Amplification with Barcoded Primers}

The extracted metagenomic DNA samples from the Ikogosi Springs were amplified with a special barcoded reverse primer 806R and a regular 515F. The reverse primer was tagged with unique 6 base pair barcode represented as (XXXXXX) for each individual sample. The sequence of the primer pair employed was $515 \mathrm{~F}$ (5'-AATGATACGGCGACCACCGAGATCTACAC TATGGTAATT GT GTGCCAGCMGCCGCGGTAA-3') and 806R barcoded primer (5'-CAAGCAGAAGACGGCATACGAGAT XXXXXX AGTCAGTCAG CC GGACTACHVGGGTWTCTAAT-3'). The PCR conditions are as described above. The amplicons were again checked on a $1.5 \%$ agarose gel (0.5X TAE) using gel electrophoresis. Thereafter they were purified to remove unused nucleotides, primers and unwanted primer dimers using the AgencourtAMPure XP bead (Beckman Coulter, Inc., CA, USA) which contains magnetic beads to purify DNA. Barcoded PCR amplicons were then eluted using $10 \mathrm{mM}$ Tris $\mathrm{pH}$ 8.5. A final validation and quantification of the barcoded V3-V4 amplicons was done 
using the Bioanalyzer-Agilent 2200 Tapestation system (Agilent Technologies Inc., CA, USA) to verify the $385 \mathrm{bp}$ fragments which include the adapters and barcode from the primers. The average size of all the samples was used to calculate the concentration of DNA in nM. Aliquots of the barcoded products were diluted as needed to a uniform concentration of $4 \mathrm{nM}$ and confirmed fluorometrically as described above.

All samples were pooled in one single tube where each sample contained a distinguishable tag unique barcode) attached to its PCR amplicon. Twenty microliters $(20 \mu \mathrm{l})$ from each sample was pooled into one single tube and the final concentration verified using the Qubit 2.0 fluorimeter to be $4 \mathrm{nM}$ before proceeding with sequencing steps.

\subsection{Denaturation of DNA Samples Prior to Sequencing}

Five microliters $(5 \mu \mathrm{l})$ of the pooled barcoded DNA samples was denatured using a 1:1 ratio of $0.2 \mathrm{~N} \mathrm{NaOH}$ and immediately kept on ice to ensure DNA strands remain separated. The denatured DNA sample was further diluted to 4 pM using the HT1 buffer from Illumina. Using similar procedure, the PhiX control DNA library supplied by Illumina, manufacturers of the MiSeq sequencing platform (Illumina Inc., CA, USA) was denatured. Subsequently the pooled sample library and the PhiX control were combined to produce a 15\% PhiX spike and subjected to heat/cold denaturation before being loaded on the Illumina MiSeq sequencing cartridge (Illumina Inc., CA, USA). To produce a 15\% spike of PhiX, $90 \mu \mathrm{l}$ of the denatured PhiX was combined with $510 \mu \mathrm{l}$ of the denatured, pooled DNA samples.

Prior to loading the cartridge onto the platform, custom Read 1

(5'-TATGGTAATT GT GTGCCAGCMGCCGCGGTAA-3'), Read 2

(5'-AGTCAGTCAG CC GGACTACHVGGGTWTCTAAT-3') and index primer (5'-ATTAGAWACCCBDGTAGTCC GG CTGACTGACT-3') were added to the MiSeq cartridge. These primers are expected to amplify the forward and reverse reads (approximately $250 \mathrm{bp}$ ) along with the index barcode (6 bp) from each barcoded DNA sample. The sequencing cartridge was then loaded unto the sequencer.

\subsection{Processing of Sequence Data Using QIIME Software}

The vast sequencing depth of this next generation sequencing method allows for an extensive capture of the microbiome structure in one sequencing run. The final sequencing run produced three main files, which included a fastqz forward read and reverse read file for the sequences of interest along with an index file with the unique barcode for each sample. The forward and reverse reads were paired using the join_paired_ends.py script in QIIME (Quantitative Insights in Microbial Ecology) [17]. Joined paired end reads were then quality filtered using the q30 standard where the probability of an incorrect base call is $99.9 \%$. Sequences that do not fit these criteria were removed. A second quality control step 
(identify_chimeric_seqs.py) was done which identifies and removes chimeric sequences. The operational taxonomic unit (OTU) table in "biom" format was then generated by picking OTUs that were aligned against the Greengenes database for 16S rDNA and also un-aligned sequence OTUs using the script (pick_reference_otus.py). Additional analysis of the OTU tables using alpha and beta diversity measures along with a taxonomy summary indicating the relative abundances for each sample was produced using bubble charts, histograms and stacked bar charts from the phinch.org website [18].

\subsection{Statistical Analysis}

To test the statistical significance of the observed relative abundancies and diversity measures of each finding, one-way ANOVAs were used at the $95 \%$ confidence limit. To assess the correlation of the relative abundancies of the different bacterial taxa with measured abiotic factors, the Pearson correlation coefficient was used.

\subsection{Metagenomic Data Repository}

All sequence data used in this study has been deposited into NCBI Sequence Read Archive with SRA numbers SAMN07728064-SAMN07728068 under the project name Ikogosi Warm Spring Bacterial Metagenomes with accession number PRJNA412736 (ID 412736).

\section{Results}

\subsection{Physical Characteristics}

Table 1 shows the physical characteristics of the spring at different locations where water samples were collected for analysis. The hottest temperature was recorded at the point of outflow of the hot spring. The spring is slightly acidic to neutral with $\mathrm{pH}$ ranging from $5.60-7.78$. The confluence of the spring was documented to have the highest $\mathrm{pH}$ value while the point of outflow of the warm spring had the lowest $\mathrm{pH}$. Opacity of the spring also increased towards the confluence of both outflows.

Table 1. Physical characteristics of Ikogosi Warm Springs.

\begin{tabular}{ccccc}
\hline $\begin{array}{c}\text { Sample } \\
\text { Designation }\end{array}$ & Location & $\begin{array}{c}\text { Temperature } \\
\left({ }^{\circ} \mathrm{C}\right)\end{array}$ & pH & Opacity $^{1}$ \\
\hline S1 & Point of Outflow of Warm Spring & 38 & 5.80 & - \\
S2 & Midpoint of Warm Spring & 38 & 7.30 & + \\
S3 & Confluence Warm and Cold Springs & 32 & 7.78 & ++ \\
S4 & Midpoint of Cold Spring & 28 & 7.60 & - \\
S5 & Designated Point of Outflow of Cold & 28 & 7.20 & + \\
& Spring & & & +
\end{tabular}

${ }^{1}(-)$ Clear $(+)$ low turbidity $(++)$ moderate turbidity. 


\subsection{Bacteria Richness and Diversity}

Table 2 presents the distribution and prevalence of various bacteria taxa in specific niches of the study sites. Out of the 417,723 genomic reads, relatively fewgenomic reads were found at the point of outflow of both cold and warm springs. Sequence reads ranged from as low as 36 genomes in S1 (the source of the warm spring) to a peak count of over 180,000 in the mesophilic confluent portion of the two springs. In general, sequence reads correlated with taxonomic diversity, and even though there were overlaps in the occurrence of species in all sampling sites, there were remarkable differences between the cold and warm spring taxonomic identity. A rarefied Chaol alpha diversity plot was generated (Figure 3) with the five sample sources using a max sampling depth of 90,893 sequences. Due to the low number of reads for sample S1 and S5 they were eliminated from the figure. As expected, the confluent of both springs (S3) had the highest diversity with greatest numbers of rare and unclassified taxa.

\subsection{Relative Abundance of Bacterial Taxa within the Different Sampling Sites}

\subsubsection{Warm Spring Source (S1)}

Expectedly, only four phyla-Firmicutes (47.2\%), Proteobacteria (44.4\%), Bacteroidetes (5.5\%) and Fusobacteria (2.7\%) were detected at source (S1) (Figure 4(a)). Bacillus sp. and other taxa within the Bacillaceae family were the most dominant within the Firmicutes phylum but with a very low number of reads compared to the midpoint of both springs and the confluence. Majority of the Proteobacteria taxa included Enterobacteraceae and Haemophilus sp. from the Gammaproteobacteria (23\%). Only the two other Proteobacteria classes (Betaproteobacteria (5\%) and Alphaproteobacteria (5.5\%)) were detected (Figure 5). There was one taxon recorded for Bacteroidetes-Prevotella sp. while the only taxa from the Fusobacterium phylum included a Fusobacterium sp. The S1 warm

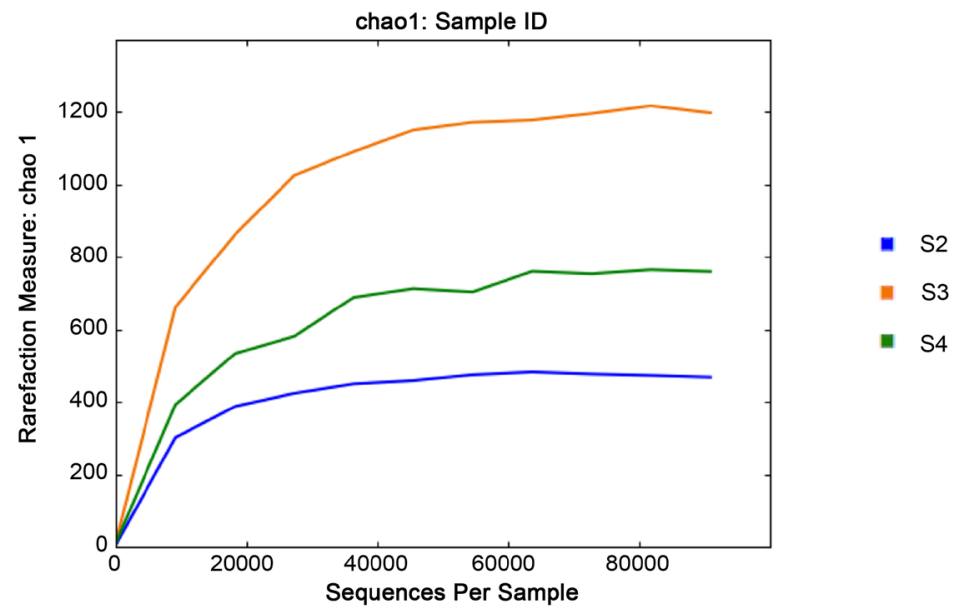

Figure 3. Chao 1 Alpha rarefaction curve showing samples S2, S3 \& S4 with a max sampling depth of 90893 sequences. S1 and S5 samples were eliminated due to the low number of reads obtained 36 and 91 respectively. Sample S3 had the greatest richness and diversity. 
Table 2. The relative distribution of the various bacteria taxa (down to the genus level) in addition to the richness and diversity (Chao 1) from each sampling site of the Ikogosi Warm Springs where S1—source of warm spring, S2_midpoint of warm spring, S3-confluence of warm and cold spring, S4-midpoint of cold spring and S5-outflow source of cold spring.

\begin{tabular}{|c|c|c|c|c|c|}
\hline & S1 & S2 & S3 & S4 & S5 \\
\hline Total number of Reads & 36 & 90,893 & 180,828 & 145,875 & 91 \\
\hline Chaol diversity index & 34 & 467 & 1160 & 757 & 36 \\
\hline No of Phylum detected & 4 & 8 & 21 & 16 & 5 \\
\hline No of Class detected & 7 & 14 & 35 & 30 & 8 \\
\hline No of Family detected & 15 & 48 & 92 & 76 & 16 \\
\hline No of Genus detected & 17 & 71 & 152 & 116 & 19 \\
\hline
\end{tabular}

(a)

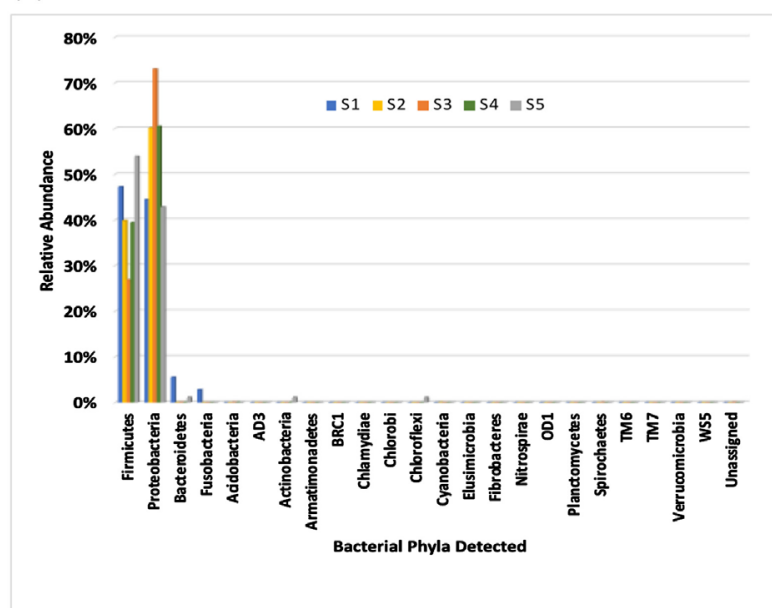

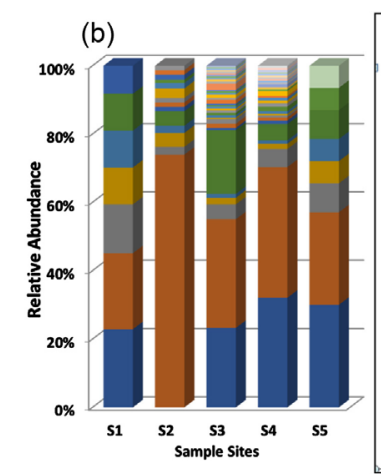

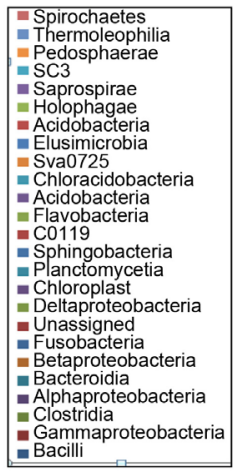

(c)
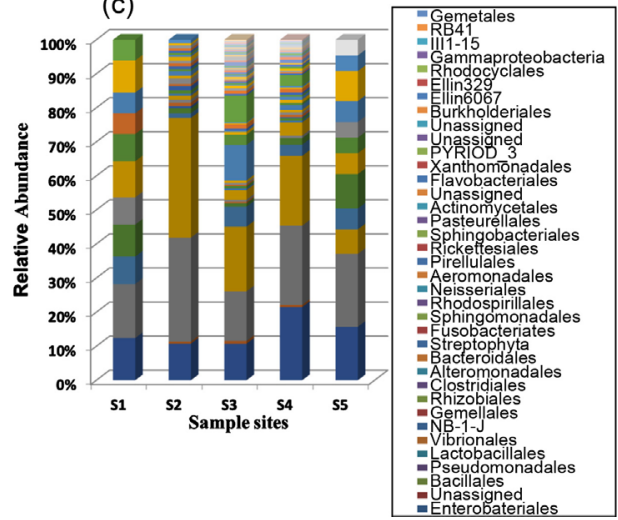
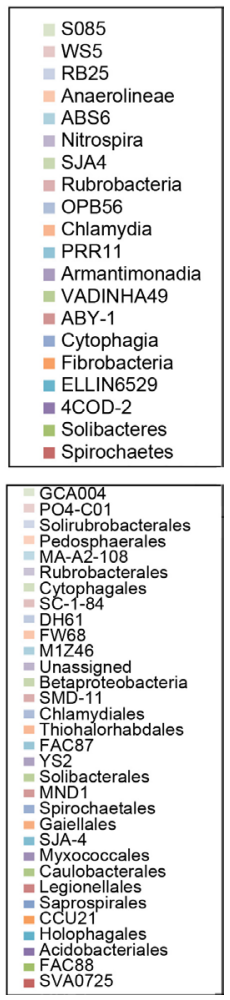

Figure 4. Relative abundance of bacterial taxa recovered from $16 \mathrm{~S}$ rDNA sequences of the 5 samples taken at different points of the Ikogosi spring at the (a) phylum level (b) class level and (c) order level. S1-source of warm spring, S2-midpoint of warm spring, S3-confluence of warm and coldspring, S4-midpoint of cold spring and S5-outflow source of cold spring.

spring source also had a few unclassified and rare bacteria within the Firmicutes phylum, however, at low read numbers that includes Peptostreptococcaceae family, Veillonella sp. and Planomicrobium sp.

\subsubsection{Midpoint of Warm Spring (S2)}

A total of eight phyla were recovered from the midpoint of the warm spring, which included the top four-Proteobacteria (60.1\%), Firmicutes (39.8\%), Cyanobacteria $(0.015 \%)$ and Bacteroidetes (0.014\%). Most of the Alpha and Betaproteobacteria members relative abundance were low (Figure 5) while the Gammaproteobacteria 


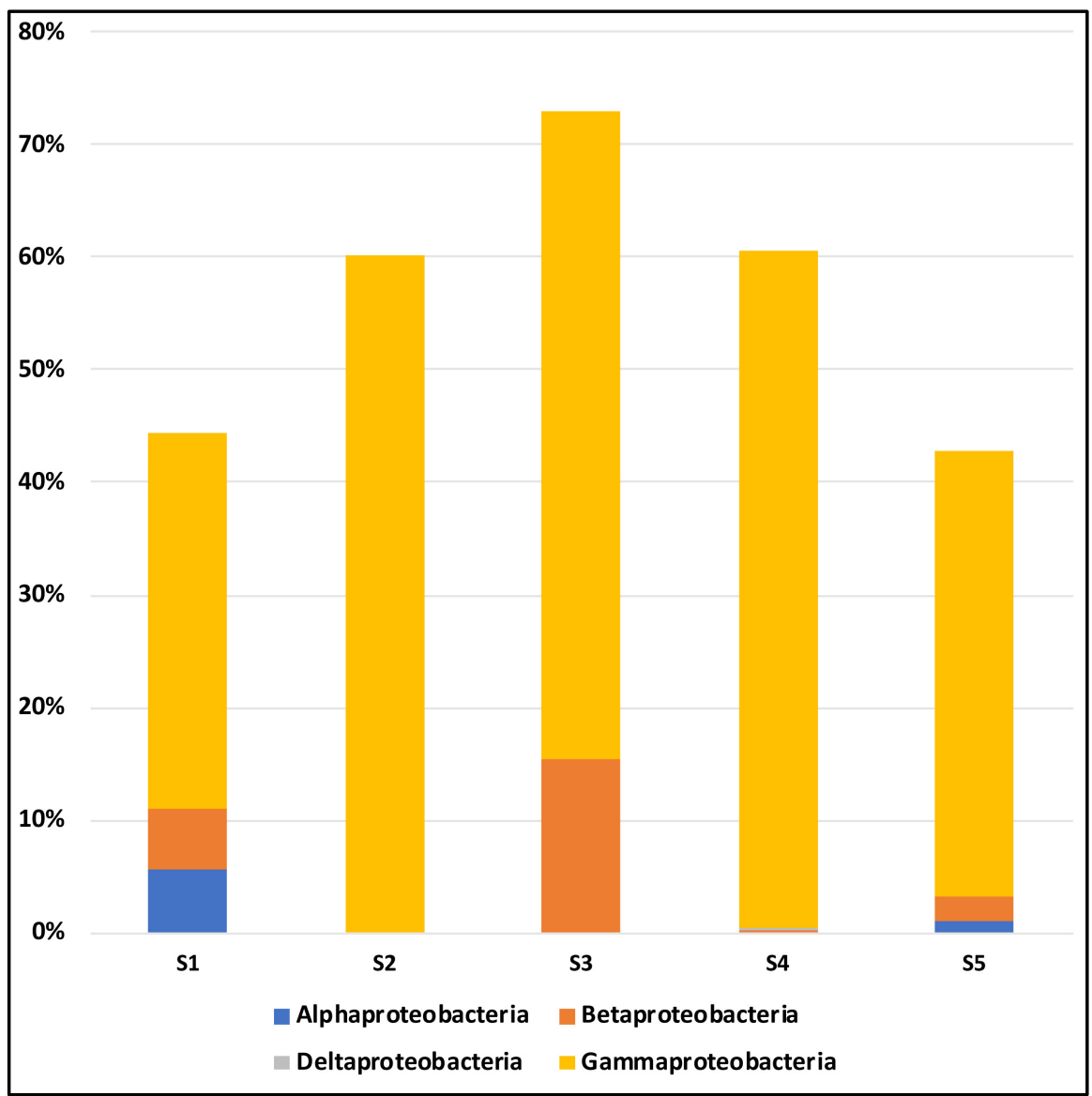

Figure 5. Relative abundance of the different classes of Proteobacteria within each sample site-S1 (warm spring outflow), S2 (midpoint of warm spring), S3 (confluence of warm and cold spring), S4 (cold spring midpoint), S5 (outflow of cold spring).

(60\%) was elevated and included taxa such as Pseudomonas sp. and Erwinia sp. In the Firmicutes phylum, this source harbored high numbers of Exiguobacterium sp. which was remarkably not found in any other samples. Other more prevalent members of the Firmicutes included Bacillus sp., Lysinibacillus sp. and unclassified taxa of the Bacillaceae family. Prevotella sp. dominated the few taxa included in the Bacteroidetes phylum. This source also contained numerous unclassified taxa from the order Streptophyta in the Cyanobacteria phylum. The midpoint of the warm spring had 13 unique taxa, which along with Exiguobacterium sp. also included Methylobacterium sp. and Jeotgallicoccus sp. (Figure $6(a))$. All 14 bacterial taxa within the warm spring source were found within the midpoint (Figure 6(b)).

\subsubsection{Confluent of Both Warm and Cold Springs (S3)}

The confluent of both springs consisted of the greatest number of phyla detected (21). The most prevalent phylum was Proteobacteria (73\%), followed by Firmicutes $(26.9 \%)$, Spirochaetes $(0.04 \%)$, Bacteroidetes $(0.03 \%)$ and Acidobacteria (0.03\%). The other phyla such as Actinobacteria, Chloroflexi, Planctomycetes had relative abundances below $0.01 \%$. The Proteobacteria were again dominated 
(a)

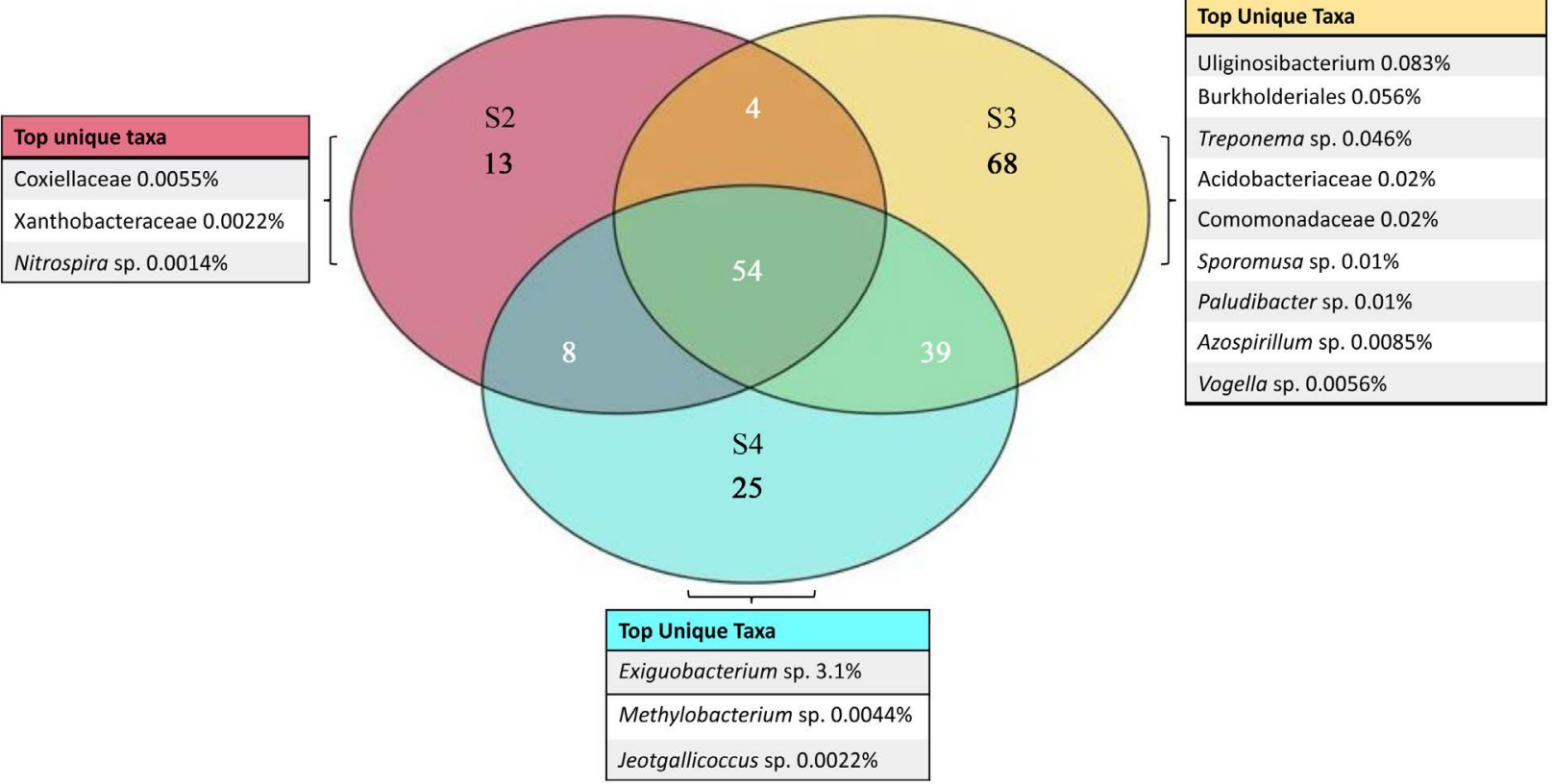

(b)
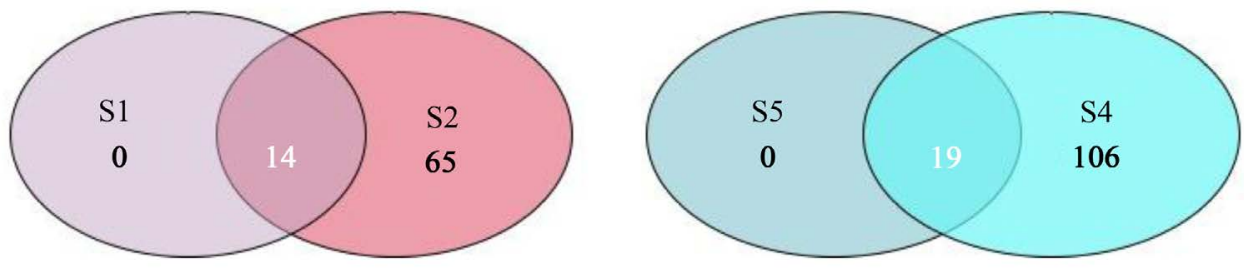

Figure 6. (a) Venn diagram depicting the shared bacterial taxa between the midpoint of the warm spring (S2), confluence of the warm and cold spring (S3) and the outflow of the cold spring (S4). The confluence of the warm and cold spring had the most unique taxa (68) not shared with the other sample sites. S4 and S3 had 25 and 13 unique taxa respectively. 54 taxa were shared between S2, S3 and S4. (b) Venn diagrams showing the shared and unique bacterial taxa between the warm spring source (S1) and its immediate outflow (S2) and the same between the cold spring source (S5) and its immediate outflow (S4).

by the Gammaproteobacteria class (58\%) with much lower numbers of Betaproteobacteria (15\%) (Figure 5). Pseudomonas sp. and taxa from the Enterobacteriaceae family dominated the Gammaproteobacteria class (Figure 4(b)) while Neisseriaceae family and Comamonas sp. were found highest under the Betaproteobacteria. The Firmicutes phylum mostly consisted of unclassified Bacillaceae members, Bacillus sp., Paenibacillus sp. and Lysinibacillus sp. The only genus that was sequenced from the phylum Spirochaetes was Treponema sp. Paludibacter sp. and Chitinophaga sp. were the most prevalent of the Bacteroidetes phylum while unclassified Acidobacteraceae family dominated the Acidobacteria phylum. The confluent of both warm and cold springs had the highest number of unique taxa (68) and included Uliginisobacterium sp., Treponema sp., Sporomusa sp. and Vogesella sp. among others (Figure 6(a)).

\subsubsection{Midpoint of Cold Spring (S4)}

The midpoint of the cold spring had 16 phyla detected which had Proteobacteria with a relative abundance of $60.5 \%$ and Firmicutes with $39.4 \%$, followed by Bacteroidetes and Actinobacteria with $0.03 \%$ and $0.02 \%$ respectively. Gammapro- 
teobacteria consisted of the majority of Proteobacteria relative abundance $(60 \%)$ and had very low numbers of Betaproteobacteria and Alphaproteobacteria $<1 \%$. Unclassified Enterobacteraceae along with Pseudomonas sp. were most prevalent within the Gammaproteobacteria class. Burkholderia sp. and Ralstonia sp. had the highest number of reads for the Betaproteobacteria class while Unclasssified Rhodospirillaceae and Sphingomonas sp. was found highest under Alphaproteobacteria. A similar abundance of Unclassified Bacillaceae, Bacillus sp. and Lysinibacillus sp. was observed under the Firmicutes phylum. Taxa within the Bacteroidetes phylum included Chryseobacterium sp. and Unclassified Chitonophagaceae while Corynebacterium sp. was found highest under Actinobacteria. This sample had 25 unique taxa not found in any other sample and included Unclassified Coxiellaceae, Xanthobacteraceae and Nitrospira sp. (Figure 6(a)). All bacteria taxa (19) found within the cold spring outflow (S5) were also identified in this midpoint sample.

\subsubsection{Outflow of Cold Spring (S5)}

The outflow of the cold spring had the second lowest number of phyla detected (5). This source was dominated by Firmicutes (53.8\%) and Proteobacteria (42.9\%). Bacteroidetes and Acidobacteria had a relative abundance of $0.03 \%$ and $0.01 \%$ respectively. Bacillus sp. and Unclassified Bacillaceae were most prominent within the Firmicutes phylum. The relative abundance of Betaproteobacteria (3\%) and Alphaproteobacteria (1\%) was higher within the sample compared to the midpoint of the cold spring. Gammaproteobacteria still had the highest relative abundance however, with $40 \%$. Unclassified Enterobacteraceae family and Serratia sp. were most abundant within the Gammaproteobacteria while Neisseria sp. and Kaistobacter sp. were the only taxa detected in Betaproteobacteria and Alphaproteobacteria respectively.

\subsection{Potential Sources of Bacterial Taxa from the Ikogosi Spring}

Figure 7 area chart shows the \# of bacterial reads detected per/100ml of sample collected. This figure shows the possible source of some key taxa detected, where similar spikes for Enterobacteriaceae were seen in the cold and warm spring source which correlated with high numbers in the confluent of both springs; more evident however from the cold spring source (S5). The figure also shows that its very likely that the major source of the high numbers of Pseudomonas sp. was not from either cold or warm spring source but could have originated from the external environment such as soil sediment along the bed of the spring or anthropogenic sources. The major source of Bacillus sp., Bacillaceae and Staphylococcus sp. taxa originated mainly from the cold and warm spring sources.

\subsection{Rare and Unclassified Taxa Detected in the Ikogosi Spring of Potential Importance}

Numerous rare and unclassified bacteria were detected mainly at the midpoint 


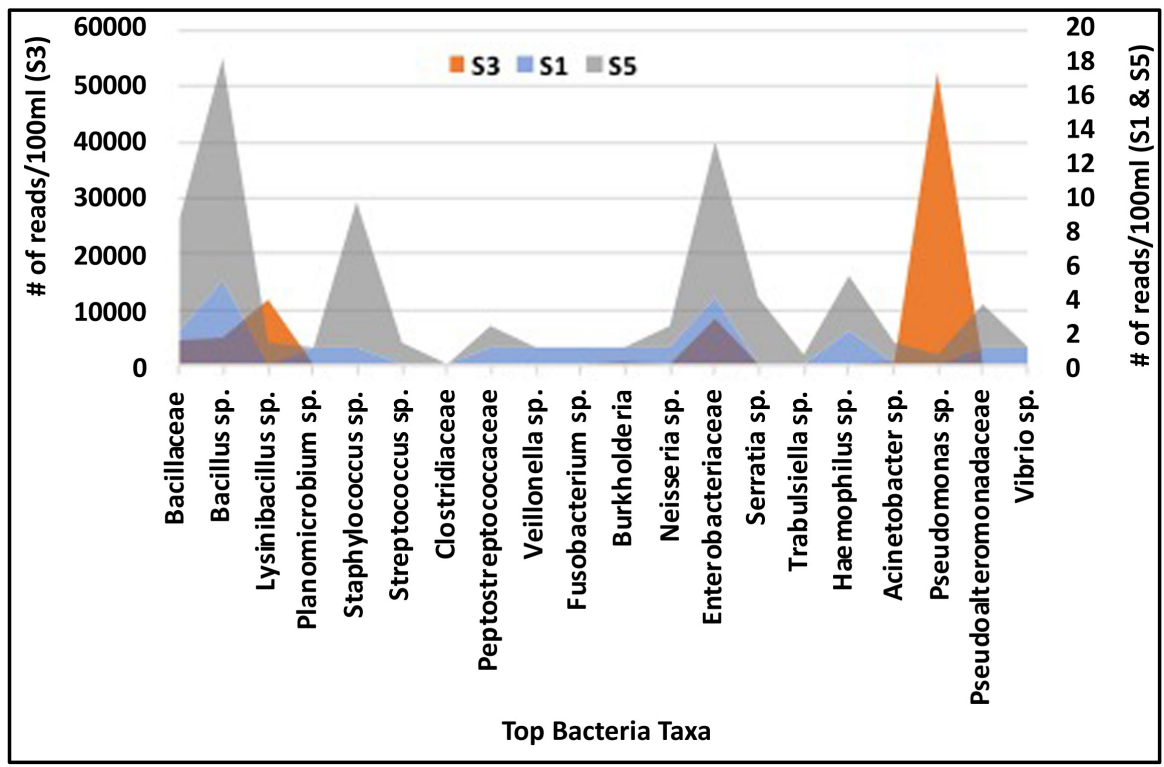

Figure 7. Area chart showing the \# of bacterial reads obtained for the top bacteria taxa within the S1-warm spring source, S5-cold spring source and S3-confluent of both warm and cold spring.

and the confluent of the warm and cold springs. The Exiguobacterium sp. had a high prevalence at the midpoint of the warm spring but was not found in any other sample site. Some of these members have the ability to survive in a range of different temperature and have been isolated from glaciers and hot springs. Some have also been able to degrade plastics such as polystyrene [19] (Table 3). The Uliginisobacterium sp. found only in the confluence of the warm and cold spring contain taxa involved in iron reduction and degradation of aromatic compounds [20] with potential for use in biodegradation of petroleum products. Numerous unclassified taxa from Acidobacteria-RB25, Ellin6075, CCU21 order were found within the midpoint outflows and the confluence of both springs with many having unknown functions within the ecosystem. A unique unclassified taxon-Rubrobacteraceae from Actinobacteria was detected in low numbers in the cold spring outflow and possess members such as Rubrobacter sp. which are thermophilic and resistant to ionizing radiation [21].

\section{Discussion}

Springs are formed when groundwater freely emerges from the subsurface of the Earth in several fractures of rocks, which eventually pools to form a stream-like flow. The warm spring of Ikogosi has been formed from fractured hard, non-foliated metamorphic rock which may have contributed to the pool of warm groundwater from great depths to the surface [31]. The near aseptic origin of spring waters makes them some of the safest drinking water sources and is believed to also have therapeutic properties [14]. Physical environmental parameters, especially temperature and $\mathrm{pH}$ have been known to be important determinants of the diversity of microbial organisms found in the environment [32] 
Table 3. Showing rare and unclassified taxa as \# of Reads/100ml recovered in the different sample site locations and their putative functions and metabolic characteristics from previous research.

\begin{tabular}{|c|c|c|c|}
\hline Rare/Unclassified Taxa & Location & \# of Reads $/ 100 \mathrm{ml}$ & Remarks \\
\hline $\begin{array}{l}\text { Exiguobacterium sp. } \\
\text { (Firmicutes) }\end{array}$ & Midpoint of warm spring & 1910 & $\begin{array}{l}\text { Ability to survive in varied temperatures-hot springs } \\
\text { and glaciers. permafrost. YT2 strain involved in } \\
\text { biodegradation of polystrene [19] }\end{array}$ \\
\hline $\begin{array}{l}\text { Uliginosibacterium sp. } \\
\text { (Proteobacteria) }\end{array}$ & $\begin{array}{l}\text { Confluence of warm and } \\
\text { cold spring }\end{array}$ & 10 & $\begin{array}{l}\text { Most members isolated from freshwater sediments. } \\
\text { Motile species involved in iron reduction, degradation of } \\
\text { aromatic compounds, denitrification [20] }\end{array}$ \\
\hline $\begin{array}{l}\text { Vogesella sp. } \\
\text { (Proteobacteria) }\end{array}$ & $\begin{array}{l}\text { Confluence of warm and } \\
\text { cold spring }\end{array}$ & 7 & $\begin{array}{l}\text { Genus consists of approximately } 5 \text { species isolated } \\
\text { from soil sediment, pond and spring water samples. } \\
\text { Aerobic and chemoheterotrophic [22] }\end{array}$ \\
\hline $\begin{array}{l}\text { Dyadobacter sp. } \\
\text { (Bacteroidetes) }\end{array}$ & Midpoint of cold spring & 5 & $\begin{array}{l}12 \text { known members including Dyadobactersoli (starch } \\
\text { degrading), Dyadobacter jianguensis (degrades methyl } \\
\text { red), Dyadobacter fermentans (associated with Zea } \\
\text { mays) [23] }\end{array}$ \\
\hline $\begin{array}{l}\text { Methylobacterium sp. } \\
\text { (Proteobacteria) }\end{array}$ & Midpoint of warm spring & 3 & $\begin{array}{l}\text { Genus consists of } 18 \text { species found in aquatic systems, } \\
\text { soil and hospital environments. Ability to use methanol, } \\
\text { formate as a sole carbon source }\end{array}$ \\
\hline RB25 class (Acidobacteria) & Cold spring outflow & 3 & $\begin{array}{l}\text { Low abundance Acidobacteria detected in sludge } \\
\text { treated soil [24] }\end{array}$ \\
\hline Ellin6075 (Acidobacteria) & $\begin{array}{l}\text { Cold spring outflow } \\
\text { Confluence of warm } \\
\text { and cold spring }\end{array}$ & $\begin{array}{l}2 \\
3\end{array}$ & $\begin{array}{l}\text { Subdivision } 4 \text { of Acidobacteria with } 2 \text { known } \\
\text { isolates-Chloroacidobacterium thermophilum } \\
\text { and a Pyrimimonas sp.-thermophilic [25] }\end{array}$ \\
\hline ABS- 6 class (AD3 phylum) & Cold spring outflow & 1 & $\begin{array}{l}\text { Dominant phyla found in cave sediment samples, } \\
\text { close lineages to Chloroflexi and Armatimonadetes } \\
\text { phyla [26] }\end{array}$ \\
\hline CCU21 order (Acidobacteria) & $\begin{array}{l}\text { Confluence of warm and } \\
\text { cold spring }\end{array}$ & 1 & $\begin{array}{l}\text { Detected and shown to be resistant to silver } \\
\text { nanoparticles in a river sediment [27] }\end{array}$ \\
\hline MB-A2-108 (Actinobacteria) & Cold spring outflow & 1 & $\begin{array}{l}\text { Closest relative-Frankia (myracanod) isolated from } \\
\text { deep marine sediments [28] }\end{array}$ \\
\hline $\begin{array}{l}\text { Rubrobacteraceae } \\
\text { (Actinobacteria) }\end{array}$ & Cold spring outflow & 1 & $\begin{array}{l}\text { Moderately thermophilic and have been isolated from } \\
\text { hot springs, species tolerate high levels of ionizing } \\
\text { radiation-Rubrobacter sp. [21] }\end{array}$ \\
\hline OPB56 (Chlorobi) & $\begin{array}{l}\text { Confluence of warm and } \\
\text { cold spring }\end{array}$ & 1 & $\begin{array}{l}\text { Recovered from Obsidian pools in Yellowstone National } \\
\text { park. Detailed phylogeny but function unknown [29] }\end{array}$ \\
\hline CO119 (Chloroflexi) & Midpoint of warm spring & 1 & No information found \\
\hline $\begin{array}{l}\text { DH61 order } \\
\text { (Planctomycetes) }\end{array}$ & $\begin{array}{l}\text { Confluence of warm and } \\
\text { cold spring }\end{array}$ & 1 & No information found \\
\hline S085 class (Chlorofexi) & Cold spring outflow & 1 & No information found \\
\hline $\begin{array}{l}\text { Candidatus Solibacter } \\
\text { (Acidobacteria) }\end{array}$ & $\begin{array}{l}\text { Confluence of warm and } \\
\text { cold spring }\end{array}$ & 1 & $\begin{array}{l}\text { Candidatus Solibacterusiaticus strain Ellin } 6067 \text { has a } \\
2 \text { - } 5 \text { times larger genome than other Acidobacteria. } \\
\text { Traits could provide metabolic, defensive and } \\
\text { regulatory advantages [30] }\end{array}$ \\
\hline
\end{tabular}


[33].

The total volume of water samples employed for genomic DNA extraction was $150 \mathrm{ml}$. In contrast to the conventional techniques which employ membrane filtration followed by lysis and elution of cells and DNA respectively, we employed a painstaking approach-successive microcentrifugation (pelleting before lysis). The scope of diversity observed at all taxonomic ranks compared to culture-based approach was much more, confirming the strength of the techniques and metagenomics in revealing genomes of microorganisms that cannot be readily obtained in pure culture [34].

Our 16S rDNA sequencing results show increased richness and diversity of the cold spring source compared to the warm spring source and where, the confluent of both springs had the most unique bacterial taxa detected. These results were confirmed in a prior study using cultivation dependent methods where the highest MPN values for bacteria were detected in the run-off from the confluent of both springs [14]. Up to $88.64 \%$ of total sequence reads were taxonomically classified, while as much as $11.5 \%$ were not matched to any known organism or sequence in the databases. The majority of the classified sequences shared similarity with the large phyla viz-Proteobacteria, Firmicutes and Bacteroidetes respectively. Proteobacteria and Firmicutes consists of several ubiquitous genera that can be found in environments with contrasting physiochemical and nutritional conditions, including moderate to elevated temperatures and $\mathrm{pH}$ as in the sites studied. On the other hand, this study found more than thirteen phylotypes downstream from source-a high diversity-representing fourteen of the thirty bacteria phyla known. Only members of the phyla Proteobacteria including Escherichia coli and Aerobacter aerogenes were recovered from a culture-based study of the ecosystem [14]. This previous study shows the staggering limitation of cultivation techniques and the need for more studies to improve recovery of bacteria from similar locations.

Proteobacteria and Firmicutes were the most versatile and prevalent phyla within all the samples, consisting of eight taxa that formed the core OTUs across $95 \%$ of samples (Table 4 ). They contained but not exhaustively-Bacillus sp. (Firmicutes), Enterobacteriaceae (Proteobacteria) and Neisseria sp. (Proteobacteria). These taxa were found in very low numbers/reads from both spring sources, but their prevalence increased drastically at the midpoint of both springs and at the confluence. These very diverse taxa, usually more resilient and copiotrophic in nature would be expected to have increased numbers as sediment run off and anthropogenic influence (washing and bathing) which impacts the amount of organic matter would lead to their higher numbers. The $\mathrm{pH}$ and temperature (Table 1) also became more neutral and ambient respectively, which would also allow sustained numbers of diverse taxa. It is worthy of note also that the water at confluence site was the most opaque among all sampled sites, due to heavy tourist influence (Table 1). Further classification of Proteobacteria in this habitat revealed that there was the presence of Gammaproteobacteria, Betaproteobacteria and Alphaproteobacteria (in order of decreasing abundance) (Figure 5). 
Table 4. Core taxa observed across $95 \%$ of all samples.

\begin{tabular}{|c|c|c|c|c|c|}
\hline & S1 & S2 & S3 & S4 & S5 \\
\hline Bacillaceae (Firmicutes) & $5.60 \%$ & $19.60 \%$ & $3.70 \%$ & $16.30 \%$ & $11 \%$ \\
\hline $\begin{array}{l}\text { Enterobacteriaceae } \\
\text { (Proteobacteria) }\end{array}$ & $16.70 \%$ & $0.12 \%$ & $6.80 \%$ & $30.70 \%$ & $15.40 \%$ \\
\hline Bacillus sp. (Firmicutes) & $19.40 \%$ & $9.20 \%$ & $4.14 \%$ & $4.30 \%$ & $22 \%$ \\
\hline $\begin{array}{l}\text { Staphylococcus sp. } \\
\text { (Firmicutes) }\end{array}$ & $2.8000 \%$ & $0.0400 \%$ & $0.0100 \%$ & $0.0700 \%$ & $14.3000 \%$ \\
\hline $\begin{array}{l}\text { Peptostreptococaceae } \\
\text { (Firmicutes) }\end{array}$ & $5.5556 \%$ & $0.0011 \%$ & $0.0005 \%$ & $0.0300 \%$ & $2.1978 \%$ \\
\hline Neisseria sp. (Proteobacteria) & $2.7778 \%$ & $0.0165 \%$ & $0.0061 \%$ & $0.0062 \%$ & $2.1978 \%$ \\
\hline $\begin{array}{l}\text { Haemophilus sp. } \\
\text { (Proteobacteria) }\end{array}$ & $8.3333 \%$ & $0.0132 \%$ & $0.0150 \%$ & $0.0110 \%$ & $5.4945 \%$ \\
\hline $\begin{array}{l}\text { Pseudoalteromonadaceae } \\
\text { (Proteobacteria) }\end{array}$ & $2.7778 \%$ & $0.0110 \%$ & $0.0105 \%$ & $0.0470 \%$ & $4.3956 \%$ \\
\hline
\end{tabular}

The warm and cold spring sources had the lowest richness and diversity with only 4 and 5 phyla detected respectively. This is expected as these spring sources originate from below the earth's surface as they are heated and filtered through rocks. Even though the richness of bacteria was low in the spring sources, Bacillus sp., other Bacillaceae family, Staphylococcus sp. and Enterobacteraceae family were consistently identified that increased in numbers substantially after the outflows (Figure 7) and may be a fingerprint for these spring sources. The cold spring was slightly more diverse and contained one rare/unclassified member of the Chloroflexi phylum-GCA004 order, only found again in the midpoint of the cold spring. This ancient branch of the bacterial tree is normally thermophilic and found in hot springs and hydrothermal vents but was found in higher numbers in the colder regions [35]. They are also likely to adapt to changes in the physiochemical environment and are considered more primitive bacteria. It is likely that as the temperature dropped the prevalence of these obligate thermophilic organisms diminished as they were no longer found along the spring.

The phylum Bacteroidetes was also observed in all the sampled sites, which makes them ubiquitous but subject to varying richness within the spring. Members of this phylum have been reported across a diverse range of fresh water and marine habitats, including temperate rivers [36] and saline hot springs [37]. Our data are congruent with those of recent studies of hot springs and freshwater bodies where the dominant presence of Proteobacteria was demonstrated [38] [39]. Only one genus of Bacteriodetes was found in both warm and cold spring sources-Prevotella sp. at very low prevalence. These organisms which can form biofilms normally form an association with humans or other animals and could indicate use of these spring sources for recreational use [40].

Worthy of note is that the phylum Fusobacteria, a group of gram-negative 
non spore formers, were found but not exclusively in the Ikogosi Warm Spring. This bacterial phylum was also reported as part of the prokaryotic biodiversity of a Malaysian circumneutral hot springs [41].

Other minor phylotypes identified at the confluence of the spring were Spirochaetes (2.5\%), Actinobacteria (2.1\%) and Acidobacteria (2.1\%). In addition, the order Pseudomonadales consisting of the genera Pseudomonas were the most abundant in this site, pathogenic genera of the order Enterobacteriales such as Enterobacter (2.6\%), Citrobacter (0.7\%) and Serratia (0.7\%) were found in the confluence of the spring. The presence of Enterobacter, Serratia and Pseudomonas spp. had also been reported in a previous study from the spring [11] [14]. However, the presence of other genera reported in this study-Lysinibacillus, Paenibacillus, Comamonas and Erwinia species were recorded for the first time in association with the spring. Numerous unclassified taxa within the diverse Acidobacteria phylum were detected in the cold spring source and cold spring midpoint which have many potentially beneficial taxa (Table 3). Most remarkably, the Exiguobacterium sp. found exclusively in the midpoint of the cold spring at a very high prevalence and from the phylum Firmicutes has been detected in very ancient ice and water sources such as permafrost and hot springs where they have the ability to survive in varied temperatures. Members have also been shown to degrade plastics [19]. This group of organisms would hold a lot of promise for bioremediation efforts, but it is still unexplainable why it is not found along other sections of the spring.

Nonetheless, a larger prokaryotic community was observed at the midpoint of the cold spring than the designated point of outflow of the cold spring. The increase in OTUs at the midpoint of the spring (S4) in comparison to the outflow of the cold spring (S5) might be due to its shallow sandy bed which is populated by tiny eukaryotes such as tadpoles and flies. The designated source of the cold spring is also hardly ever visited by tourists hence the low water turbidity.

There was overall a large presence of taxonomically unassigned sequences observed mostly across midpoint of each spring and the confluence of both springs. This suggests that there are novel prokaryotic populations and possibly gene-pool in this unique spring. Studies dedicated to improving the cultivability of microbes are critically needed to explore and harness the potential biotechnological and industrial value of such bioresources.

\section{Conclusion}

This study presents a considerable diversity of microbial communities at the confluence of the in the Springs of Ikogosi, sharply contrasting the sparse diversity of only 4 phyla recovered by culture methods in previous reports. Nonetheless, the very low bacterial richness and diversity at the source of the warm and cold springs, dominated by Firmicutes (Bacillus sp. and Staphylococcus sp.) and Proteobacteria (Enterobacteraceae family) phyla was suggestive of an impressive microbiological quality of the groundwater sources of the Spring in Ikogosi. The 
hike in bacteria abundance and diversity at the confluence indicates the possible origin of the organisms to be the geo-ecological surroundings receiving the spring outflow. Our report emphasizes the power of culture independent amplicon metagenomics, in providing insights into microbial genetic diversity, community composition, distribution and abundance in natural habitats. A closeup analysis shows a more diverse bacterial community in samples collected from the cold spring which also overlapped with some taxa present in the warm spring environment. Finally, we reported several unassigned/unclassified sequences in this study, which could be new bacteria. It is acknowledged that culturing these unclassified organisms is critical to advancing knowledge of their origins and potential applications in Bioeconomy. To the best of our understanding, this study is the first to present a report using a culture independent technique to explore the prokaryotic community of the Ikogosi Warm Springs in Nigeria.

\section{Conflicts of Interest}

The authors declare that the research was conducted in the absence of any commercial or financial relationships that could be construed as a potential conflict of interest.

\section{References}

[1] Talabi, A.O. (2013) Hydrogeochemistry and Stable Isotopes ( $\delta 18 \mathrm{O}$ and $\delta 2 \mathrm{H})$ Assessment of Ikogosi Spring Waters. American Journal of Water Resources, 1, 25-33.

[2] Hairul, N.B.I., Ojo, K.A., Kasimu, M.A., Gafar, O.Y., Okoloba, V. and Mohammed, S.A. (2013) Ikogosi Warm Water Resorts: What you don't know? Interdisciplinary Journal of Contemporary Research in Business, 4, 280-303.

[3] Ojo, O.M. and Agbede, O.A. (2014) Assessment of Ikogosi Warm Spring Water Quality in Ekiti State, South Western Nigeria. Sci-Afric Journal of Scientific Issues, Research and Essays, 2, 116-123.

[4] Oladipo, A.A., Oluyemi, E.A., Tubosun, I.A., Fasisi, M.K. and Ibitoye F.I. (2005) Chemical Examination of Ikogosi Warm Spring in South Western Nigeria. Journal of Applied Sciences, 5, 75-79. https://doi.org/10.3923/jas.2005.75.79

[5] Tekere, M., Lotter, A., Olivier, J., Jonker, N. and Venus, S. (2011) Metagenomic Analysis of Bacterial Diversity of Siloam Hot Water Spring, Limpopo, South Africa. African Journal of Biotechnology, 10, 18005-18012. https://doi.org/10.5897/AJB11.899

[6] Chen, K. and Patcher, L. (2005) Bioinformatics for Whole-Genome Shortgun Sequencing of Microbial Communities. PLoS Computational Biology, 1, 24. https://doi.org/10.1371/journal.pcbi.0010024

[7] Krause, L., Diaz, N.N., Bartels, D., Edwards, R., Pühler, A., Rohwer, F., Meyer, F. and Stoye, J. (2006) Finding Novel Genes in Bacterial Communities Isolated from the Environment. Bioinformatics, 22, 281-289. https://doi.org/10.1093/bioinformatics/btl247

[8] Petrosino, J.F., Highlander, S., Luna, R.A., Gibbs, R.A. and Versalovic, J. (2009) Metagenomic Pyrosequencing and Microbial Identification. Clinical Chemistry, 55, 856-866. https://doi.org/10.1373/clinchem.2008.107565 
[9] Varley, J. and Scott, P.T. (1998) Conservation of Microbial Diversity A Yellowstone Priority. The News Magazine of the American Society for Microbiology, 64, 147-151.

[10] Tekere, M., Lotter, A., Olivier, J. and Venter, S. (2015) Bacterial Diversity in Some South African Thermal Springs: A Metagenomic Analysis. Proceedings of World Geothermal Congress, 1-8.

[11] Olajuyigbe, F. and Ajele, J. (2005) Production Dynamics of Extracellular Protease from Bacillus Species. African Journal of Biotechnology, 4, 776-779.

[12] Lozupone, C.A. and Knight, R. (2007) Global Patterns in Bacterial Diversity. Proceedings of the National Academy of Sciences of the United States of America, 104, 11436-11440. https://doi.org/10.1073/pnas.0611525104

[13] Feng, B., Li, X., Wang, J., Hu, Z., Meng, H., Xiang, L. and Quan, Z. (2009) Bacterial Diversity of Water and Sediment in the Changjiang Estuary and Coastal Area of the East China Sea. FEMS Microbiology Ecology, 70, 236-248. https://doi.org/10.1111/j.1574-6941.2009.00772.x

[14] Adeyeye, E. and Fagbohun, E.D. (2011) Physical, Chemical and Microbiological Analysis of Ikogosi Warm Spring in Nigeria. International Journal of Pharmaceutical Sciences Review and Research, 6, Article No. 1.

[15] Xia, N., Xia, X., Zhu, B., Zheng, S. and Zhuang, J. (2013) Bacterial Diversity and Community Structure in the Sediment of the Middle and Lower Reaches of the Yellow River, the Largest Turbid River in the World. Aquatic Microbial Ecology, 71, 43-55. https://doi.org/10.3354/ame01664

[16] Bergmann, G.T., Bates, S.T., Eilers, K.G., Lauber, C.L., Caporaso, J.G., Walters, W.A., et al. (2011) The under-Recognized Dominance of Verrucomicrobia in Soil Bacterial Communities. Soil Biology and Biochemistry, 43, 1450-1455. https://doi.org/10.1016/j.soilbio.2011.03.012

[17] Caporaso, J.G., Kuczynski, J., Stombaugh, J., Bittinger, K., Bushman, F.D., Costello, E.K., et al. (2010) QIIME Allows Analysis of High-Throughput Community Sequencing Data. Nature Methods, 7, 335-336. https://doi.org/10.1038/nmeth.f.303

[18] Bik, H.M. (2016) Phinch: An Interactive, Exploratory Data Visualization Framework for-Omic Datasets.

[19] Yang, Y., Yang, J., Wu, W., Zhao, J., Song, Y., Gao, L., Yang, R. and Jiang, L. (2015) Biodegradation and Mineralization of Polystyrene by Plastic-Eating Mealworms: Part 2. Role of Gut Microorganisms. Environmental Science \& Technology, 49, 12087-12093. https://doi.org/10.1021/acs.est.5b02663

[20] Han, J., Baek, K., Ahn, Y., et al. (2018) Uliginosibacter iumsangjuense sp. nov., Isolated from Sediment of the Nakdong River. Antonie van Leeuwenhoek, 111, 259-264. https://doi.org/10.1007/s10482-017-0946-Z

[21] Albuquerque, L., Johnson, M.M., Schumann, P., Rainey, F.A. and da Costa, M.S. (2014) Description of Two New Thermophilic Species of the Genus Rubrobacter, Rubrobacter calidifluminis sp. nov. and Rubrobacter naiadicus sp. Nov., and Emended Description of the Genus Rubrobacter and the Species Rubrobacter bracarensis. Systematic and Applied Microbiology, 37, 235-243. https://doi.org/10.1016/j.syapm.2014.03.001

[22] Sheu, S., Chen, J., Young, C. and Chen, W. (2013) Vogesellafluminis sp. nov., Isolated from a Freshwater River, and Emended Description of the Genus Vogesella. International Journal of Systematic and Evolutionary Microbiology, 63, 3043-3049. https://doi.org/10.1099/ijs.0.048629-0

[23] Wang, L., Chen, L., Ling, Q., Li, C., Tao, Y. and Wang, M. (2015) Dyadobacter 
jiangsuensis sp. nov., a Methyl Red Degrading Bacterium Isolated from a DyeManufacturing Factory. International Journal of Systematic and Evolutionary Microbiology, 65, 1138-1143. https://doi.org/10.1099/ijs.0.000069

[24] Miranda, A., William Mendes, L., Barbosa Rocha, S.M., Van den Brink, P.J., Melgaço Bezerra, W., Maciel Melo, V.M., Lopes Antunes, J.E. and Ferreira Araujo A.S. (2018) Responses of Soil Bacterial Community after Seventh Yearly Applications of Composted Tannery Sludge. Geoderma, 318, 1-8.

https://doi.org/10.1016/j.geoderma.2017.12.026

[25] Eichorst, S.A., Trojan, D., Roux, S., Herbold, C., Rattei, T. and Woebken, D. (2018) Genomic Insights into the Acidobacteria Reveal Strategies for Their Success in Terrestrial Environments. Environmental Microbiology, 20, 1041-1063. https://doi.org/10.1111/1462-2920.14043

[26] Ji, M., Greening, C., Vanwonterghem, I., Carere, C.R., Bay, S.K., Steen, J.A., Montgomery, K., Lines, T., Beardall, J., van Dorst, J., et al. (2017) Atmospheric Trace Gases Support Primary Production in Antarctic Desert Surface Soil. Nature, 552, 400-403. https://doi.org/10.1038/nature25014

[27] Welz, P.J., Khan, N. and Prins, A (2018) The Effect of Biogenic and Chemically Manufactured Silver Nanoparticles on the Benthic Bacterial Communities in River Sediments. Science of The Total Environment, 644, 1380-1390.

https://doi.org/10.1016/j.scitotenv.2018.06.283

[28] Reed, D.W., Fujita, Y., Delwiche, M.E., Blackwelder, D.B., Sheridan, P.P., Uchida, T. and Colwell, F.S. (2002) Microbial Communities from Methane Hydrate-Bearing Deep Marine Sediments in a Forearc Basin. Applied and Environmental Microbiology, 68, 3759-3770. https://doi.org/10.1128/AEM.68.8.3759-3770.2002

[29] Hiras, J., Wu, Y.W., Eichorst, S.A., Simmons, B.A. and Singer, S.W. (2016) Refining the Phylum Chlorobi by Resolving the Phylogeny and Metabolic Potential of the Representative of a Deeply Branching, Uncultivated Lineage. The ISME Journal, 10, 833-845. https://doi.org/10.1038/ismej.2015.158

[30] Challacombe, J.F., Eichorst, S.A., Hauser, L., Land, M., Xie, G. and Kuske, C.R. (2011) Biological Consequences of Ancient Gene Acquisition and Duplication in the Large Genome of Candidatus Solibacterusitatus Ellin6076. PLOS ONE, 6, e24882. https://doi.org/10.1371/journal.pone.0024882

[31] Ikudayisi, A., Adeyemo, F. and Adeyemo, J. (2015) Chemical and Hydro-Geologic Analysis of Ikogosi Warm Spring Water in Nigeria. International Journal of Geological and Environmental Engineering, 9, 1126-1130.

[32] Jiménez, D.J. and Zambrano, M.M. (2014) Metagenome of Acidic Hot Spring Microbial Planktonic Community: Structural and Functional Insights. In: Encyclopaedia of Metagenomics, Springer, New York, 1-8. https://doi.org/10.1007/978-1-4614-6418-1_173-2

[33] Lakshmanan, V., Selvaraj, G. and Bais, H.P. (2014) Functional Soil Microbiome: Below Ground Solutions to an Aboveground Problem. Plant Physiology, 166, 689-700. https://doi.org/10.1104/pp.114.245811

[34] Kunin, V., Copeland, A., Lapidus, A., Mavromatis, K. and Hugenholtz, P. (2008) A Bioinformatician's Guide to Metagenomics. Microbiology and Molecular Biology Reviews, 72, 557-578. https://doi.org/10.1128/MMBR.00009-08

[35] Pérez, V., Cortés, J., Marchant, F., Dorador, C., Molina, V., Cornejo-D’Ottone, M., Hernández, K., Jeffrey, W., Barahona, S. and Hengst, M.B. (2020) Aquatic Thermal Reservoirs of Microbial Life in a Remote and Extreme High Andean Hydrothermal System. Microorganisms, 8, 208. https://doi.org/10.3390/microorganisms8020208 
[36] Bockelmann, U., Manz, W., Neu, T.R. and Szewzyk, U. (2000) Characterization of the Microbial Community of Lotic Organic Aggregates ('River Snow') in the Elbe River of Germany by Cultivation and Molecular Methods. FEMS Microbiology Ecology, 33, 157-170. https://doi.org/10.1016/S0168-6496(00)00056-8

[37] Tenreiro, S., Nobre, M.F., Rainey, F.A., Miguel, C. and da Costa, M.S. (1997) Thermonemarossianum sp. Nov., a New Thermophilic and Slightly Halophilic Species from Saline Hot Springs in Naples. Italy. International Journal of Systematic Bacteriology, 47, 122-126. https://doi.org/10.1099/00207713-47-1-122

[38] Badhai, J., Ghosh, T.S. and Das, S.K. (2015) Taxonomic and Functional Characteristics of Microbial Communities and Their Correlation with Physicochemical Properties of Four Geothermalsprings in Odisha, India. Frontiers in Microbiology, 6, 1166. https://doi.org/10.3389/fmicb.2015.01166

[39] Panda, A.K., Bisht, S.S., De Mandal, S. and Kumar, N.S. (2016) Bacterial and Archeal Community Composition in Hot Springs from Indo-Burma Region, North-East India. AMB Express, 6, 111. https://doi.org/10.1186/s13568-016-0284-y

[40] Mukherjee, N., Bartelli, D., Patra, C., Chauhan, B.V., Dowd, S.E. and Banerjee, P. (2016) Microbial Diversity of Source and Point-of-Use Water in Rural Haiti: A Pyrosequencing-Based Metagenomic Survey. PLOS ONE, 11, e0167353. https://doi.org/10.1371/journal.pone.0167353

[41] Chan, C.S., Chan, K., Ee, R., Hong, K., Urbieta., M.S., Donati, E.R., Shamsir, M.S. and Goh, K.M. (2017) Effects of Physiochemical Factors on Prokaryotic Biodiversity in Malaysian Circumneutral Hot Springs. Frontiers in Microbiology, 8, 1252. https://doi.org/10.3389/fmicb.2017.01252 